\title{
Structural, Optoelectronic, and Photoelectrochemical Investigation of CdSe NC's Prepared by Hot Injection Method
}

\author{
Sunil V. Barma, ${ }^{1}$ Sachin R. Rondiya, ${ }^{2}$ Yogesh A. Jadhav, ${ }^{1}$ Sagar B. Jathar, ${ }^{1}$ Ganesh K. Rahane, ${ }^{1}$ Avinash V. Rokade, ${ }^{1}$ Russell W.
} Cross, ${ }^{2}$ Mamta P. Nasane, ${ }^{1}$ Vijaya S. Jadkar, ${ }^{1}$ Nelson Y. Dzade ${ }^{2}$ and Sandesh R. Jadkar ${ }^{1,3,{ }^{*}}$

\begin{abstract}
In this study, we report the synthesis and characterization of CdSe nanocrystals (NC's) by facile hot injection (HI) method. The formation of CdSe NC's was confirmed by X-ray diffraction (XRD), Raman spectroscopy, and X-ray photoelectron spectroscopy (XPS). The optical properties were analyzed by UV-visible and photoluminescence (PL) spectroscopy shows an excitonic peak at $617 \mathrm{~nm}$ in PL spectra corresponds to the band gap of $\sim 2 \mathrm{eV}$ favourable for optoelectronic device applications. The Photoelectrochemical (PEC) performance of CdSe thin film prepared by spin coating method demonstrates a rise of photocurrent density $\left(\mathrm{J}_{\mathrm{sc}}=0.081 \mathrm{\mu Acm}^{-2}\right)$ after illumination. The Mott-Schottky (MS) and electrochemical impedance spectroscopy (EIS) measurements were further carried out to understand intrinsic properties namely the type of conductivity, flat band potential, charge carrier density $\left(\mathrm{N}_{\mathrm{D}}\right)$, charge transfer resistance, and recombination lifetime. The n-type conductivity, the charge carrier density of $N_{D}=1.292 \times 10^{16} \mathrm{~cm}^{-3}$, and recombination lifetime of $32.4 \mu$ s suggest the ideal behaviour of CdSe NC's for device quality photoelectrodes.
\end{abstract}

Keywords: CdSe NC's; Hot-injection method; Photoelectrochemical cell; Water splitting.

Received:25 November 2020; Accepted date: 12 December 2020.

Article type: Research article.

\section{Introduction}

Energy consumption in the last few decades is increased rapidly with an increase in population as well as the civilized lifestyle. To meet ever-growing demand of energy, an alternate energy resources apart from the conventional energy sources (e. g. fossil fuel, coal, and natural gases) has to be used and replaced with more environmentally friendly, abundant, and easily available source. Hydrogen can play an important role in the energy supply in the future. ${ }^{[1]}$ Electricity can be generated directly from hydrogen using fuel cells, or hydrogen can be burned in conventional combustion engines. At present, hydrogen is mostly produced by reforming natural gas. Moreover, hydrogen can also be created using the electrolysis of water. A photoelectrochemical (PEC) cell is a device that directly extracts electrical energy or produces useful fuels

\footnotetext{
${ }^{1}$ School of Energy Studies, Savitribai Phule Pune University, Pune 411007, India.

${ }^{2}$ School of Chemistry, Cardiff University, Main Building, Park Place, Cardiff, CF10 3AT, Wales, UK.

${ }^{3}$ Department of Physics, Savitribai Phule Pune University, Pune 411007, India.

*Email: sandesh@physics.unipune.ac.in (S. R. Jadkar)
}

through a process called the electrolysis of water to hydrogen and oxygen. ${ }^{[2]}$ For this process, it uses a non-conventional energy source i.e. solar energy. Solar hydrogen will play a significant role in the perspective of a sustainable and ecofriendly source because it is clean, storable, and transportable. PEC device consists of a semiconducting electrode, also auxiliary metal, and a reference electrode immersed in a liquid electrolyte. To produce hydrogen sustainably and costeffectively, the PEC device offers a resourceful approach. However, it is suffering from lower solar to hydrogen (STH) conversion efficiency. ${ }^{[3]}$ Various semiconductor materials such as $\mathrm{TiO}_{2}, \mathrm{ZnO}, \mathrm{Fe}_{2} \mathrm{O}_{3}$, and $\mathrm{CdS}$ have been investigated and modified to improve the STH conversion efficiency. ${ }^{[4-6]}$ However, due to low photoresponse and high charge-carrier recombination rate, STH conversion efficiency is still low. Therefore, a search for an efficient semiconductor for PEC application is still going on.

Recently, semiconductor compounds like $\mathrm{CdSe}, \mathrm{PbS}, \mathrm{PbSe}$, etc. have received great attention as a photon harvester due to their favorable properties such as size-dependent electronic structure, large extinction coefficient, and multiple exciton generation. ${ }^{[7-11]}$ These semiconducting materials have band gap in the range of 1-3 eV and absorb most of the visible energy of the electromagnetic spectrum which made them a potential 
candidate for application in a wide range of optoelectronic field viz photodetectors, sensors, light-emitting diode (LEDs), optical waveguide and solar cells. ${ }^{[12-15]}$ Cadmium selenide (CdSe) is one of group II-VI semiconductor material that has been extensively studied because of its desired band gap, large absorption coefficient, and exceptional electronic properties. ${ }^{[16,17]}$ Also, it has been shown a great promise for photoelectrochemical conversion. ${ }^{[18,19]}$ Moreover, the various synthetic routes namely the solvothermal, sonochemical, single-molecule precursor, microwave irradiation, nonorganometallic precursor, and organometallic precursor route can be used to synthesize the CdSe in a control and costeffective manner for desired application. ${ }^{[20-24]}$

Herein a present report, CdSe NC's has been synthesized by a facile, low cost, HI technique. Subsequently, the structural and optical properties of CdSe NC's were studied using XRD, Raman spectroscopy, UV-Visible spectroscopy, XPS, and PL spectroscopy. The application of thin-films in water splitting is governed by photocurrent density, charge transfer resistance, flat band potential, charge carrier density, and recombination lifetime of charge carriers. The electrochemical characterizations like chronoamperometry, EIS, MS, and Bode-plot measurements were performed to understand the PEC performance of CdSe thin film for water splitting.

\section{Experimental Section}

\subsection{Chemicals}

Cadmium Sulphate $\left(\mathrm{CdSO}_{4}, \geq 99 \%\right)$, Selenium Powder (Se, $\geq 99 \%$ ), Oleylamine (OAm, $\geq 99 \%$ ), Oleic acid (OA, $\geq 99 \%$ ), Isopropanol (IPA, $\geq 99.5 \%$ ), toluene ( $\geq 99.8 \%$ ), purchased from Sigma-Aldrich and were used as received.

\subsection{Synthesis of CdSe NC's}

In a typical synthesis, $2 \mathrm{mmol}$ of $\mathrm{CdSO}_{4}$ powder was dissolved in $10 \mathrm{~mL}$ of OAm and $1 \mathrm{~mL}$ of OA in a three-neck flask. The solution was degassed at $150{ }^{\circ} \mathrm{C}$ for $30 \mathrm{~min}$ to remove dissolved oxygen and moisture. The Se precursor was prepared separately by stirring $2 \mathrm{mmol}$ Se powder in $5 \mathrm{ml}$ of OAm for $30 \mathrm{~min}$. After degassing, the temperature of the solution was raised to $250{ }^{\circ} \mathrm{C}$ followed by injection of $5 \mathrm{~mL}$ of the Se-precursor solution as shown in Fig.1. The reaction was allowed to proceed at $250^{\circ} \mathrm{C}$ for the next $10 \mathrm{~min}$ for nanocrystal growth. The reaction was quenched by a cold water bath.

\subsection{Post synthesis treatment and film preparation}

During purification and cleaning of prepared CdSe NC's, the solution of $4 \mathrm{~mL}$ of toluene and $40 \mathrm{ml}$ of IPA is added to CdSe colloidal solution for the precipitation, followed by centrifugation at $5000 \mathrm{rpm}$ for $5 \mathrm{~min}$. The supernatant was discarded, and the process was repeated four times. The precipitate was dried under an infrared (IR) lamp to collect the powder sample. For the film preparation, CdSe NC's sample was re-dispersed in toluene $(50 \mathrm{mg} / \mathrm{mL})$ and the solution is sonicated $30 \mathrm{~min}$. The CdSe NC's ink is then spin-coated over the FTO substrate at $2000 \mathrm{rpm}$ for $30 \mathrm{sec}$ and repeated 3 times. The prepared photoelectrodes were annealed at $150{ }^{\circ} \mathrm{C}$ and used for the PEC measurements.

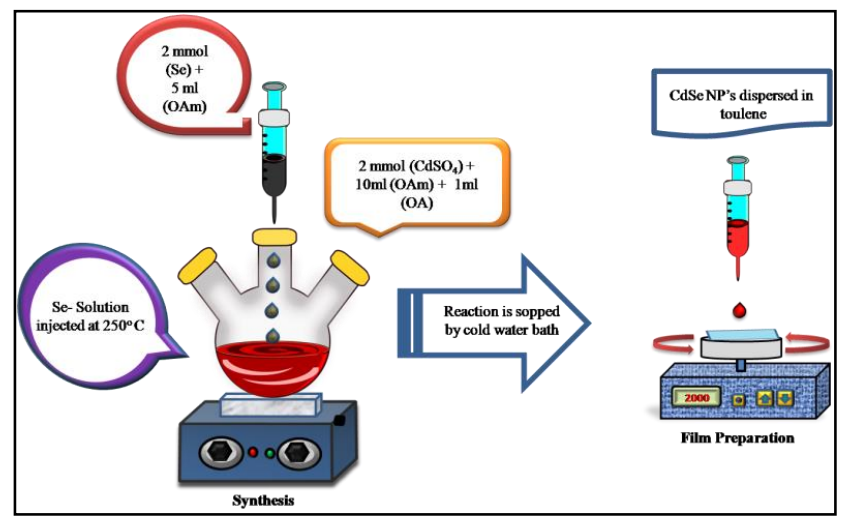

Fig. 1 Schematics of synthesis of CdSe NC's by hot injection method and film preparation of CdSe NC's by spin coating method.

\section{Characterization of films}

\subsection{Structural and optical characterization}

The structural and optical properties of as-synthesized CdSe $\mathrm{NC}$ 's were systematically investigated using different characterization techniques viz. XRD, Raman spectroscopy, UV-Visible spectroscopy, and PL spectroscopy. The average crystalline size, lattice parameter, and phase identification of NC's were studied using X-ray diffraction (Bruker D8 Advance, Germany make) with $\mathrm{Cu}-\mathrm{K}_{\alpha}$ radiation $(\lambda=1.54 \AA)$. The Raman spectra of NP were recorded by using a microRaman spectrometer (Renishaw, UK at the KBSI Gwangju Centre) by employing a He-Ne laser source of the wavelength of $532 \mathrm{~nm}$ at $0.1 \mathrm{~mW}$ power. The optical property of NC's was investigated from absorbance spectra measured using a JASCO, V-670 UV-Visible spectrophotometer in the range of 400-1000 nm. The PL spectra were recorded using Edinburgh Instrument FLS980 spectrophotometer. XPS studies were carried out using Thermo Scientific, K-alfa, UK machine with a resolution of $0.1 \mathrm{eV}$. The spectra have been recorded for the specific element using Al-K $\alpha$ radiation.

\subsection{Photoelectrochemical (PEC) measurements}

The PEC performance i.e. Chronoamperommetry, electrochemical impedance spectroscopy (EIS), potential scan measurement of CdSe thin films (area $1 \mathrm{~cm}^{2}$ ) as the working electrode was carried out in $0.5 \mathrm{M} \mathrm{Na}_{2} \mathrm{SO}_{4}(\mathrm{pH}=7)$ solution as an electrolyte using Potentiostat/Galvanostat AUTOLAB PGSTAT302N (Switzerland). Saturated calomel electrode (SCE) and Pt were used as reference and counter electrodes, respectively. The photo response measurement was carried out on a solar simulator having a $150 \mathrm{~W}$ Xenon lamp (PEC-L01) with an illumination intensity of $100 \mathrm{~mW} / \mathrm{cm}^{2}$ (AM 1.5) as reported in earlier literature. ${ }^{[25]}$ 

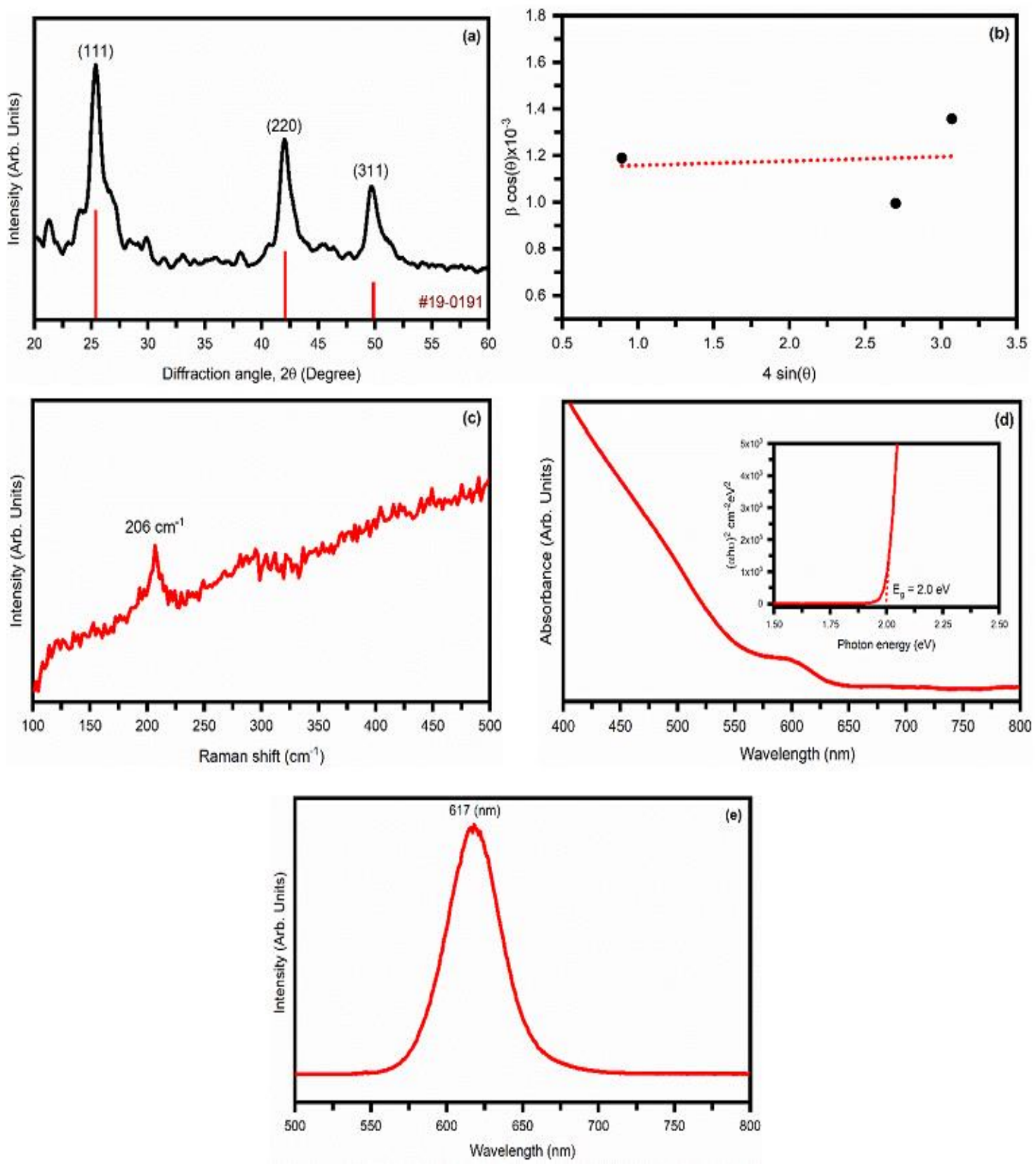

Fig. 2 (a) XRD pattern (b) Williamson-Hall (W-H) plot (c) Raman spectrum (d) UV-vis absorbance spectra and inset Tauc plot (e) $\mathrm{PL}$ spectra of CdSe NC's dissolved in toluene.

\section{Results and discussion}

Fig. 2(a) shows the XRD pattern of as-synthesized CdSe NC's prepared by the hot injection method. The prominent peaks observed at $2 \theta \sim 25.33^{\circ}, 42.01^{\circ}$, and $49.77^{\circ}$ correspond to diffraction from (111), (220) and (311) crystal planes, respectively. The experimental data for cubic crystal structure is in very good agreement with the JCPDS Card No \#19-0191 as well as with the previous study. ${ }^{[26]}$ The average crystallite size $\left(\mathrm{d}_{\mathrm{X} \text {-ray }}\right)$ was calculated using the Debye-Scherer equation, ${ }^{[27]}$

$$
\mathrm{d}_{\mathrm{x}-\text { ray }}=\frac{0.9 \lambda}{\beta \cos \theta_{\mathrm{B}}}
$$

Where $\lambda$ is the wavelength of the $\mathrm{Cu}-\mathrm{K}_{\alpha}$ line and $\beta$ is the full width at half maximum (FWHM) of diffraction peak. The calculated value of $\mathrm{dx}_{\mathrm{X} \text {-ray }}$ is $8.5 \mathrm{~nm}$.

The interplanar spacing between atoms $\left(\mathrm{d}_{\mathrm{hkl}}\right)$ for CdSefilm is calculated using Bragg's law,

$$
2 \mathrm{~d}_{\mathrm{hkl}} \sin \theta=\mathrm{n} \lambda
$$

The lattice constant $(a=b=c)$ of CdSe films were determined from interplanar spacing $\left(\mathrm{d}_{\mathrm{hkl}}\right)$ by using, ${ }^{[28]}$

$$
\mathrm{a}=\mathrm{d}_{\mathrm{hkl}} \sqrt{\mathrm{h}^{2}+\mathrm{k}^{2}+\mathrm{l}^{2}}
$$

The dislocation density $(\delta)$ is the length of dislocation lines per unit volume of the crystal and was calculated using the Williamson-Smallman formula, ${ }^{[29]}$

$$
\delta=\frac{\mathrm{n}}{\mathrm{d}_{\mathrm{x}-\mathrm{ray}}^{2}}
$$



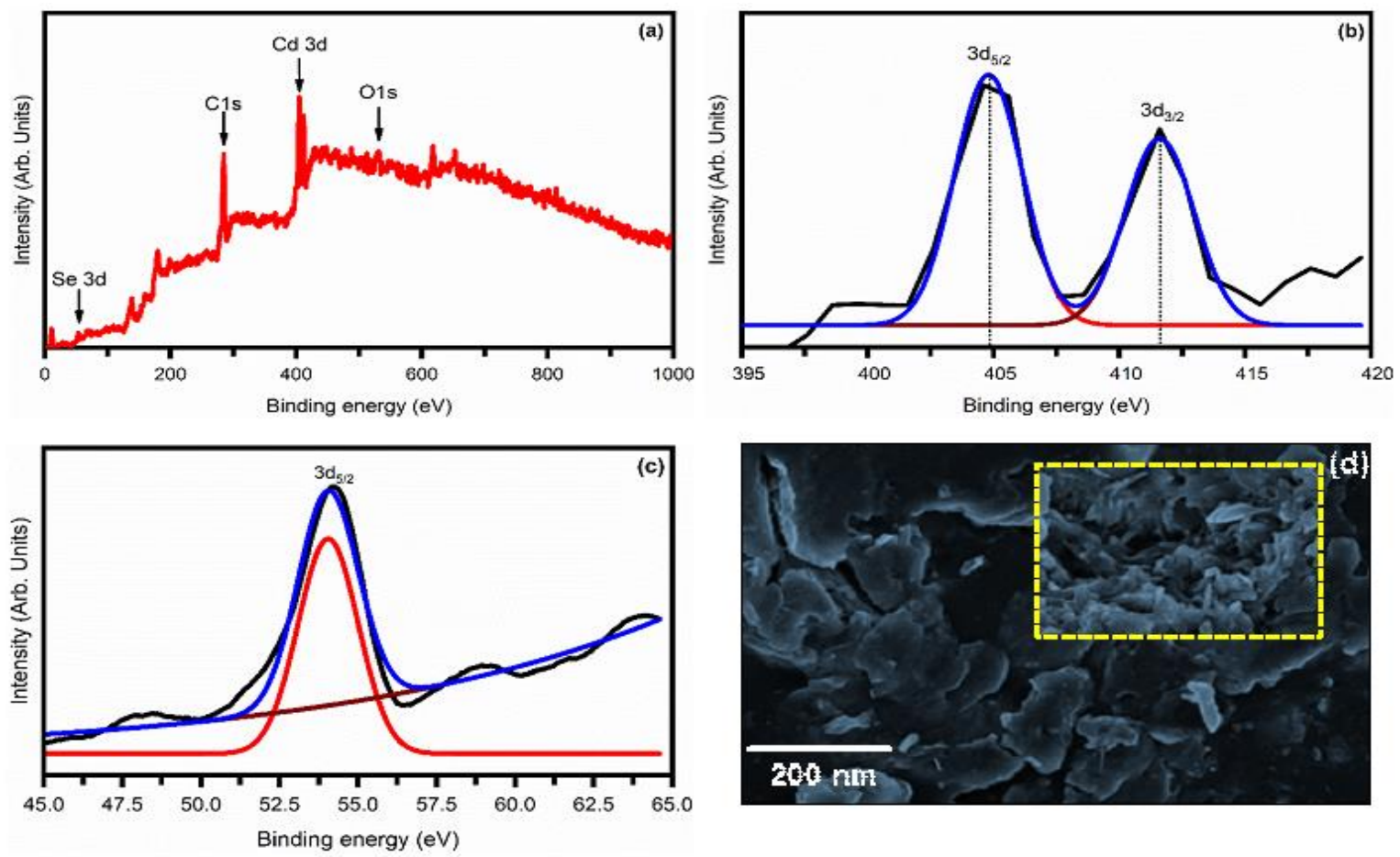

Fig. 3 X-ray photoelectron spectrum (XPS) of CdSe sample (a) Survey scan, (b) Cd-3d, (c) Se-3d, and (d) SEM image of CdSe NC's.

where $\mathrm{n}$ is the factor which is equal to unity for minimum dislocation density and $\mathrm{d}_{\mathrm{x} \text {-ray }}$ is particle size. The micro-strain is calculated using the slope of Williamson-Hall (W-H) plot shown in Fig. 2(b) by using equation, ${ }^{[29]}$

$$
\varepsilon=\frac{\beta \operatorname{Cos} \theta}{4}
$$

The calculated value of $\mathrm{d}_{\mathrm{hkl}}, \epsilon$, and $\delta$ are $\sim 3.51 \AA, \sim 1.86 \times 10^{-}$ 5 , and $\sim 1.38 \times 10^{16} \mathrm{~m}^{-2}$, respectively.

Fig. 2(c) shows the Raman spectra of CdSe NC's recorded on powder sample with an excitation wavelength of $532 \mathrm{~nm}$ and resolution of $1 \mathrm{~cm}^{-1}$ at $0.5 \mathrm{~mW}$ of laser power. The peak at $\sim 206 \mathrm{~cm}^{-1}$ corresponds to the first order CdSe longitudinal optical phonon (LO) of the mode corresponding to the lowenergy shoulder originates from surface optical phonon modes (SO). ${ }^{[30,31]}$ Fig. 2(d) shows the UV-Visible absorption spectra of CdSe NC's disperse in toluene, shows strong absorption over visible and near UV-region which is good for photovoltaic application. The PL spectra of CdSe NC's dispersed in toluene recorded with an excitation wavelength of $460 \mathrm{~nm}$ at room temperature are shown in Fig. 2(e). The narrow emission band observed at $\sim 617 \mathrm{~nm}$ corresponds to band gap of $2 \mathrm{eV}$, which is closed to reported data. ${ }^{[32]}$ The oxidation states of prepared CdSe film was systematically investigated using XPS analysis. Fig. 3(a-c) represent the survey scan, core-level spectra of Cd-3d and Se-3d, respectively. In the XPS survey spectra of a CdSe film, all the peaks were identified for $\mathrm{Cd}, \mathrm{Se}, \mathrm{C}$, and $\mathrm{O}$. The $\mathrm{C} 1 \mathrm{~s}$ peak at $284.6 \mathrm{eV}$ was taken as the internal standard and all the peak positions were normalized to it. The peaks at $\sim 404 \mathrm{eV}, \sim 411$ $\mathrm{eV}$, and $\sim 54 \mathrm{eV}$ attributed to $\mathrm{Cd}-3 \mathrm{~d}_{5 / 2}, \mathrm{Cd}-3 \mathrm{~d}_{3 / 2}$, and $\mathrm{Se}-3 \mathrm{~d}$, respectively, corresponding to the binding energy of $\mathrm{CdSe}$
$\mathrm{NC}^{\prime} \mathrm{s} .{ }^{\left[{ }^{33]}\right]}$ A uniform distribution of CdSe NC's can be seen from the scanning electron microscope (SEM) image as shown in Fig. 3(d). Overall, CdSe NCs do not have any definite structure and morphology with agglomerated singular size particles. However, a rod-like structure coming out of a larger indistinguishable structural particle can see from the SEM image. Further, the PEC performance of CdSe NC's was investigated on a set up as shown in Fig. 4 consists of three electrodes, electrochemical work station, and solar simulator.

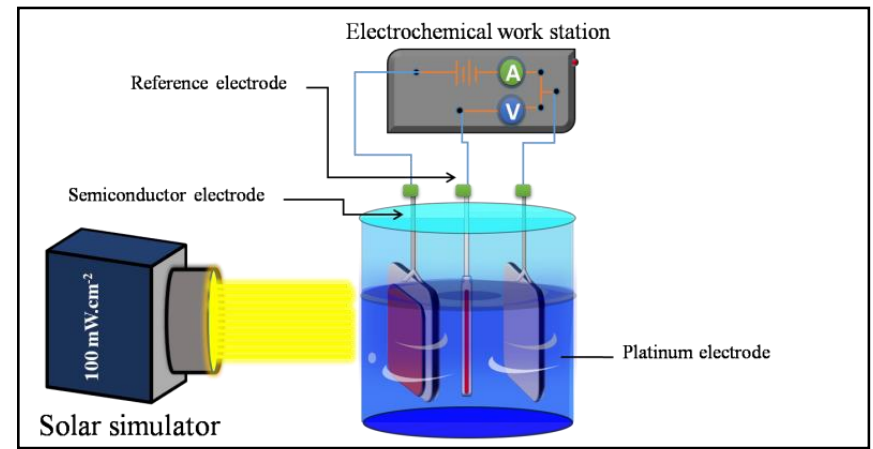

Fig. 4 Schematic of the Photoelectrochemical measurements setup, consists of 3 electrodes reference, working, and counter.

Fig. 5(a) depicts amperometric photocurrent density-time profile (light Chopping) for CdSe NC's measured at an applied bias of $0.5 \mathrm{Vs}$ SCE. The prepared photoelectrode shows immediate enhancement in photoresponse under illuminated conditions. Whenever photon hits photoelectrode, it generates the electron-hole pair with some efficiency of generation. These photogenerated electrons and holes further separate and travel through the semiconductor in opposite directions. The 
holes drive the oxygen evaluation reaction (OER) at the surface of the semiconductor working electrode. Whereas the electrons are travel to the rear ohmic contact and through an electrical connection to the surface of the counter electrode to drive the hydrogen evaluation reaction (HER). A photocurrent difference of $0.081 \mu \mathrm{Acm}^{-2}$ between dark conditions (OFF state) and under illumination (ON state) was observed. Also, the small current was observed in dark conditions due to nonfaradic reaction. Fig. 5(b) shows the MS plot of CdSe film to evaluate intrinsic properties such as flat band potential $\left(\mathrm{V}_{\mathrm{fb}}\right)$ and charge carrier density $\left(\mathrm{N}_{\mathrm{D}}\right)$. Each point on the MS curve represents the value of capacitance at semiconductorelectrolyte junction measured at respective potential $(\mathrm{V})$ using the following equations:

$$
\begin{gathered}
\mathrm{C}^{-2}=\left(\frac{2}{\varepsilon_{\mathrm{S}} \varepsilon_{\mathrm{o}} \text { e } \mathrm{N}_{\mathrm{D}}}\right)\left(\mathrm{V}-\mathrm{V}_{\mathrm{fb}}-\frac{\mathrm{kT}}{\mathrm{e}}\right) \\
\mathrm{N}_{\mathrm{D}}=\left(\frac{2}{\varepsilon_{\mathrm{S}} \varepsilon_{\mathrm{o}} \mathrm{eS}}\right)
\end{gathered}
$$

where $\varepsilon_{0}$ is the permittivity of free space, $\varepsilon_{\mathrm{s}}$ is the dielectric constant of the semiconductor (for CdSe, $\varepsilon_{\mathrm{s}}=9.5^{[34]}$ ), e is the electronic charge, $\mathrm{k}$ is Boltzmann's constant, $\mathrm{V}$ is biased
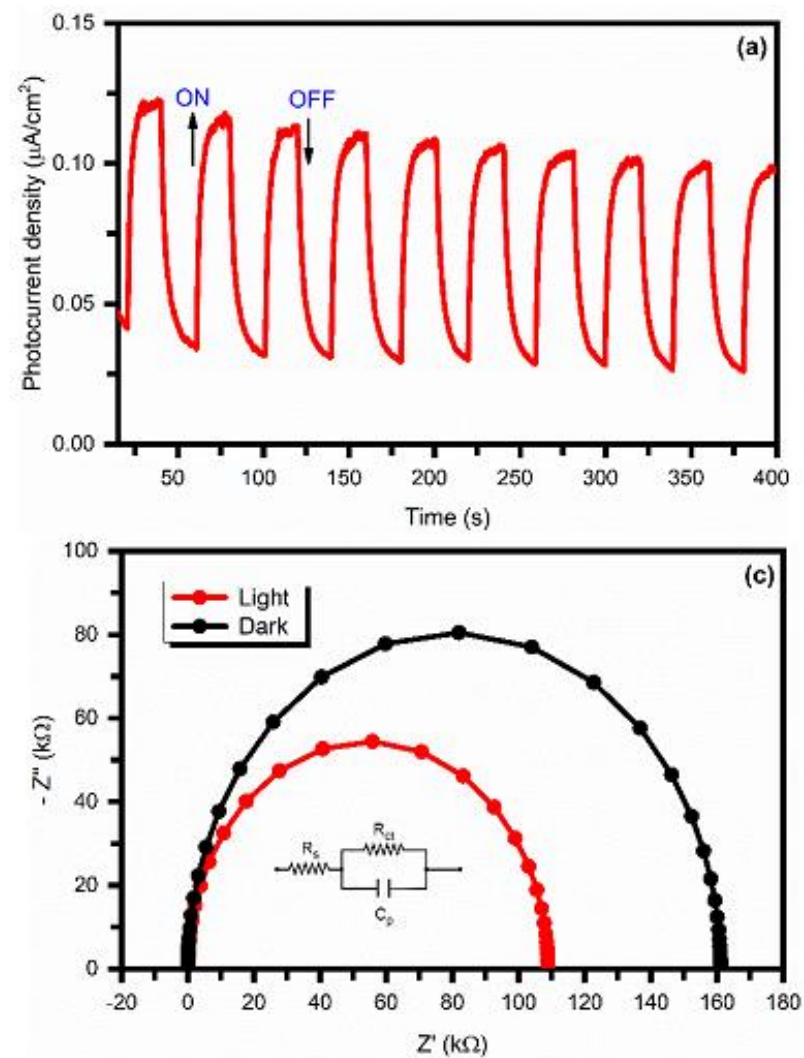

potential and $\mathrm{V}_{\mathrm{fb}}$ is flat band potential, $\mathrm{S}$ is the slope and $\mathrm{T}$ is the temperature (in Kelvin). ${ }^{[35]}$ The positive slope of the MS curve indicates the n-type conductivity of CdSe NC's. Moreover, the extrapolation of the MS curve on the $\mathrm{x}$-axis gives the value of $\mathrm{V}_{\mathrm{fb}}$ which is $-0.12 \mathrm{~V}_{\mathrm{RHE}}$ for CdSe NC's. The value of $\mathrm{V}_{\mathrm{fb}}$ was further used to calculate $\mathrm{N}_{\mathrm{D}}$ from equation (3). The calculated value of $\mathrm{N}_{\mathrm{D}}$ is $1.29 \times 10^{16} \mathrm{~cm}^{-3}$. The higher value of $\mathrm{N}_{\mathrm{D}}$ is favourable for PEC application as more value of $\mathrm{N}_{\mathrm{D}}$ reflects more conductivity. To know the change of electrochemical performance under dark and illumination, frequency-dependent electrochemical measurement of $\mathrm{CdSe}$ film has been carried out. Electrochemical impedance spectroscopy (EIS) of CdSe film performed in the frequency range of $0.1 \mathrm{~Hz}$ to $100 \mathrm{kHz}$. EIS data provides the Nyquist diagrams i.e. the imaginary impedance versus the real impedance. Moreover, the change in phase of the applied sinusoidal waves with applied frequency i.e. bode-phase plot was obtained from the EIS data. Nyquist diagram of CdSe was obtained from EIS data by fitting the data to the equivalent circuit model. The evaluation of the Nyquist plot provides the
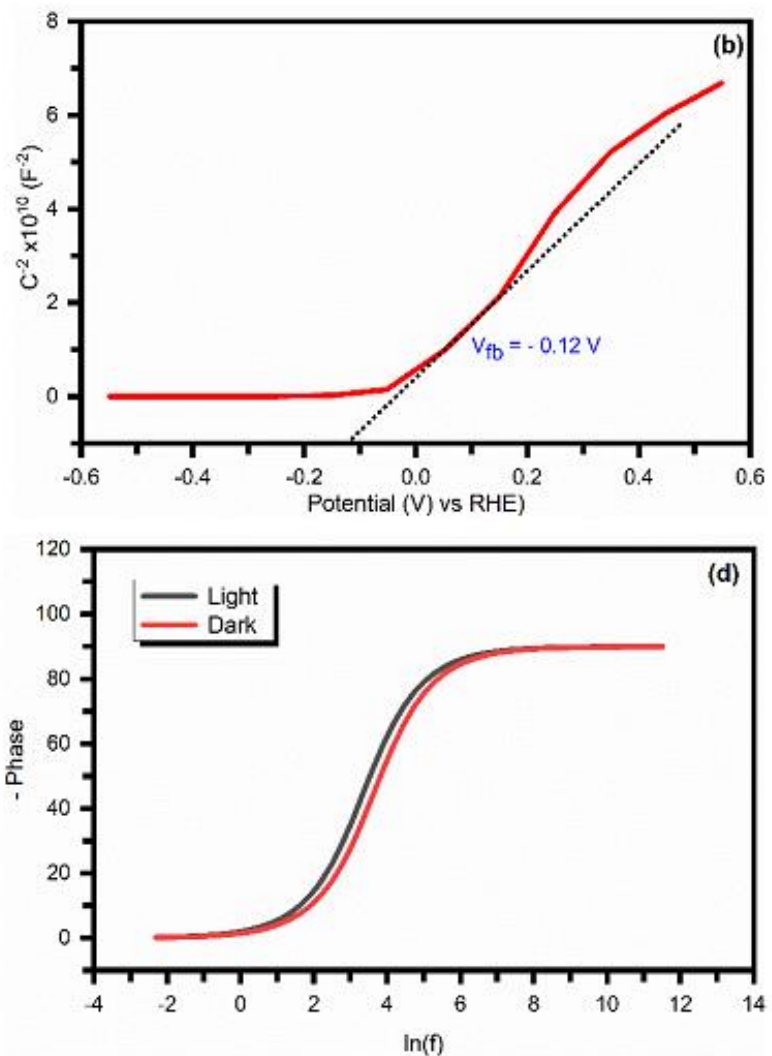

Fig. 5 (a) Photocurrent response under pulsed illumination (b) Mott-Schottky plot (c) Nyquist plot (d) Bode plot of CdSe film.

Table 1Summarised photoelectrochemical analysis data for CdSe NC's. The contact, charge transfer resistance $\left(\mathrm{R}_{\Omega}, \mathrm{R}_{\mathrm{ct}}\right)$, capacitance $\left(C_{p}\right)$, current density $\left(\mathrm{J}_{\mathrm{sc}}\right)$, carrier lifetime $(\tau)$, donor concentration $\left(\mathrm{N}_{\mathrm{D}}\right)$ under dark and illumination conditions.

\begin{tabular}{ccccccccc}
\hline CdSe NPs & $\mathbf{R}_{\boldsymbol{\Omega}}(\boldsymbol{\Omega})$ & $\mathbf{R}_{\mathbf{c t}}(\mathbf{K} \boldsymbol{\Omega})$ & $\mathbf{C}_{\mathbf{p}}(\mathbf{n f})$ & $\mathbf{V}_{\mathbf{f b}}\left(\mathbf{V}_{\mathbf{R H E}}\right)$ & $\mathbf{N}_{\mathbf{D}}\left(\mathbf{c m}^{-\mathbf{3}}\right)$ & $\mathbf{f}_{\mathbf{m a x}}(\mathbf{H z})$ & $\boldsymbol{\tau}(\boldsymbol{\mu s})$ & $\mathbf{J}_{\mathbf{s c}}\left(\boldsymbol{\mu A c m} \mathbf{c m}^{-\mathbf{2}}\right)$ \\
\hline Dark & 15.23 & 161 & 34.5 & -0.12 & $1.292 \times 10^{16}$ & 8.6 & 29.3 & 0.0342 \\
Light & 15.23 & 108 & 38.2 & --- & --- & 8.5 & 32.4 & 0.1152 \\
\hline
\end{tabular}


information about the ohmic resistance i.e. series resistance, charge transfer resistance at the photoelectrode/electrolyte interface, and the capacitance of the thin film shown in Fig. 5 (c). The high frequency (corresponding to low Z") intercept on the real axis (i.e. Z" axis) represents the ohmic series resistance which is $\left(\mathrm{R}_{\Omega}\right)$. There is a resistance between electrical contact of the electrode-electrolyte and resistivity of the electrolyte solution. Whereas $\mathrm{R}_{\mathrm{ct}}$ and $\mathrm{C}$ are the charge transfer resistance and double-layer capacitance at the electrode-electrolyte interface, respectively given in Table 1. A small semicircle in the Nyquist plot indicates an effective charge transfer process with lower charge transfer resistance at the electrode-electrolyte interface. CdSe NC's shows a smaller semicircle in Nyquist plot under illumination than a semicircle in the dark state which suggests a decrease in charge transfer resistance at the electrode-electrolyte interface after illumination. Fig. 5(d) displays the Bode-phase plot of the CdSe film. Bode-phase assists to evaluate an important parameter to illustrate PEC activity is the lifetime $(\tau)$ of the electrons i.e. recombination time by the frequency (f) at which highest phase change observed by the expression:

$$
\tau=\frac{1}{2 \pi \mathrm{f}}
$$

The calculated value of recombination time is given in a Table 1. The phase angle of CdSe film under illumination conditions is higher than that for dark, which means it shows good electrochemical behaviour. From the PEC investigation, it is noticed that the CdSe photoelectrode shows very promising results like quick photoresponse, the better life-time of the charge carriers, and decreased charge transfer resistance which is the ideal behaviour of the device quality photoelectrode.

\section{Conclusions}

In summary, we have successfully synthesized CdSe NC's by a facile and low-cost hot injection method. The $\mathrm{x}$-ray diffraction (XRD), Raman spectroscopy, and $\mathrm{x}$-ray photoelectron spectroscopy (XPS) reveal the formation of cubic phase CdSe NC's having crystallite size of $8.5 \mathrm{~nm}$. The scanning electron microscope (SEM) image demonstrates the uniform distribution of $\mathrm{CdSe}$ thin film prepared by the spin coating method. A photocurrent density $\left(\mathrm{J}_{\mathrm{sc}}\right)$ of $0.081 \mu \mathrm{Acm}^{-2}$, charge carrier density $\left(\mathrm{N}_{\mathrm{D}}\right)$ of $1.292 \times 10^{16} \mathrm{~cm}^{-3}$, and a significant decrease in charge transfer resistance after the illumination is fascinating properties of $\mathrm{CdSe}$ thin film. However, a further improvement is possible by proper selection of electrolyte (with optimum $\mathrm{pH}$ ), suitable charge collection contact, and annealing of the film in an adequate environment. Water splitting, PEC solar cell, and photodetector are the future potential application of CdSe thin film.

\section{Acknowledgment}

SachinRondiya, Russell Cross, and Nelson Dzadeacknowledge the UK Engineering and Physical Sciences Research Council (EPSRC) for funding (Grant No.
EP/S001395/1). Yogesh Jadhav thanks SPPU PDF (Grant No. SPPU-PDF/ ST/CH/2019/0004) and School of Energy Studies, SPPU for financial support and access to laboratory facilities. Sandesh Jadkar is thankful to the University Grants Commission (UPE program), New Delhi, and Indo-French Centre for the Promotion of Advanced Research-CEFIPRA, Department of Science and Technology, New Delhi for special financial support.

\section{Conflict of Interest}

There is no conflict of interest.

\section{Supporting Information}

Not Applicable

\section{References:}

[1] J.A. Turner, Science, 2004, 305, 972-974, doi: 10.1126/science. 1103197.

[2] K. Maeda and K. Domen, J. Phys. Chem. Lett., 2010, 1, 26552661, doi:10.1021/jz1007966.

[3] J. Zhang and X. Wang, Angew. Chemie, 2015, 54, 7230-7232, doi: $10.1002 /$ anie.201502659.

[4] T. Hisatomi and J. Kubota, K. Domen, Chem. Soc. Rev., 2014, 43, 7520-7535, doi: 10.1039/c3cs60378d.

[5] C. Liu, J. Tang, H.M. Chen, B. Liu and P. Yang, Nano Lett., 2013, 13, 2989-2992, doi: 10.1021/n1401615t.

[6] X. Chen, S. Shen, L. Guo and S.S. Mao, Chem. Rev., 2010, 110, 6503-6570, doi: 10.1021/cr1001645.

[7] P. Kamat, K. Tvrdy, D. Baker and J. Radich, Chem. Rev., 2010 110, 6664-6688, doi: 10.1021/cr100243p.

[8] A. Nozik, M. Beard, J. Luther, M. Law, R. Ellingsong and J. Johonson, Chem. Rev., 2010, 110, 112-147, doi: 10.1017/CBO9781139022750.006.

[9] G. Hodes, J. Phys. Chem. C, 2008, 112, 17778-17787, doi: 10.1021/jp803310s.

[10] I. Mora-Seró and J. Bisquert, J. Phys. Chem. Lett., 2010, 1, 3046-3052, doi: 10.1021/jz100863b.

[11] J. Sambur, T. Novet and B. Parkison, Science, 2011, 330, 63-67, doi: 10.1126/science.1191462.

[12] J. Xu, J. Liu, D. Cui, M. Gerhold, A. Y. Wang, M. Nagel and T. K. Lippert, Nanotechnology, 2007, 18, 025403, doi: 10.1088/0957-4484/18/2/025403.

[13] G. Konstantatos, L. Levina, A. Fischer and E. Sargent, Nano Lett., 2008, 8, 1446-1450, doi: 10.1021/n1080373e.

[14] G. Banfi, V. Degiorgio and D. Fortusini, Tech. Dig. - Eur. Quantum Electron. Conf., 1996, 21, 120, doi: 10.1364/ol.21.001490.

[15] I. Gur, N. Fromer and A. Alivisatos, J. Phys. Chem. B, 2006, 110, 25543-25546, doi: 10.1021/jp0652852.

[16] T. Logu, K. Sankarasubramanian, P. Soundarrajan and K. Sethuraman, Electron. Mater. Lett., 201, 206-212, doi: 10.1007/s13391-014-3335-z.

[17] W. Yu, L. Qu, W. Guo and X. Peng, Chem. Mater., 2003, 15, 2854-2860. doi: 10.1021/cm034081k. 
[18] K. Tsvetkova and K. Kochev, Sol. Energy Mater. Sol. Cells, 1993, 31, 429-435, doi:10.1016/0927-0248(93)90135-P.

[19] S. Mahato and A. Kar, J. Electroanal. Chem., 2015, 742, 23 29, doi: 10.1016/j.jelechem.2015.01.034.

[20] S. Cumberland, K. Hanif, A. Javier, G. Khitrov, G. Strouse, S. Woessner and C. Yun, Chem. Mater., 2002, 14, 1576-1584, doi: $10.1021 / \mathrm{cm} 010709 \mathrm{k}$.

[21] D. Crouch, P. O’brien, M. Malik, P. Skabara and S. Wright, Chem. Commun., 2003, 3, 1454-1455, doi: 10.1039/b301096a.

[22] U. Gautam, M. Rajamathi, F. Meldrum, P. Morgan and R. Seshadri, Chem. Commun., 2001,629-630. doi: 10.1039/b009394g.

[23] J. Ge, Y. Li and G. Yang, Chem. Commun., 2002, 18261827, doi:10.1039/b203230a.

[24] J. Hambrock, A. Birkner and R. A. Fischer, J. Mater. Chem., 2001, 11, 3197-3201, doi: 10.1039/b104231a.

[25] A. Rokade, S. Rondiya, V. Sharma, M. Prasad, H. Pathan and S. Jadkar, J. Solid State Electrochem., 2017, 21, 2639-2648, doi: 10.1007/s10008-016-3427-9.

[26] Z. Meng, L. Zhu, S. Ye, Q. Sun, K. Ullah, K. Cho and W. Oh, Nanoscale Res. Lett., 2013, 8, 1-10., doi: 10.1186/1556276X-8-189.

[27] B. Cullity and S. Stock, 3rd Edition, Princeton Hall (2001). [28] P. Annie Vinosha, L. Ansel Mely, J. EmimaJeronsia, S. Krishnan, and S. Jerome Das, Optik, 2017, 134,99-108, 10.1016/j.ijleo.2017.01.018.

[29] G. Williamson and R. Smallman, Philos. Mag., 1956, 1, 34 46, doi:10.1080/14786435608238074.

[30] F. Comas, N. Studart and G. Marques, Solid State Commun., 2004, 130, 477-480, doi: 10.1016/j.ssc.2004.02.037.

[31] H. Lange, M. Artemyev, U. Woggon and C. Thomsen, Nanotechnology, 2009, 20, 045705, doi:10.1088/09574484/20/4/045705.

[32] X. Peng, L. Manna, W. Yang, J. Wickham, E. Scher, A. Kadavanich and A. Alivisatos, Nature., 2000, 404, 59-61, doi: 10.1038/35003535.

[33] C. Vargas-Hernández, V. Lara, J. Vallejo, J. Jurado and O. Giraldo, Phys. Status Solidi Basic Res., 2005, 242, 1897-1901, doi: 10.1002/pssb.200461717.

[34] K. Young and H. Frederikse, J. Phys. Chem. Ref. Data., 1973, 2, 313-410. doi:10.1063/1.3253121.

[35] C. Windisch and G. Exarhos, J. Vac. Sci. Technol. A, 2000, 18, 1677-1680, doi: 10.1116/1.582406.

\section{Author information}

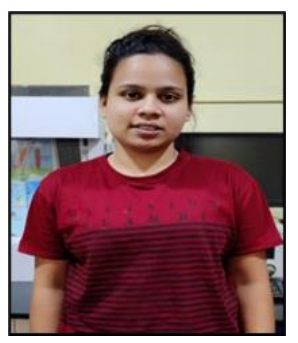

Mamta P. Nasane is currently working as a Research Scholar at School of Energy Studies, Savitribai Phule Pune University, and Pune, India. Her research interest is An Interlinked ComputationalExperimental Investigation into SnS Nano-Flakes for Field Emission Application.

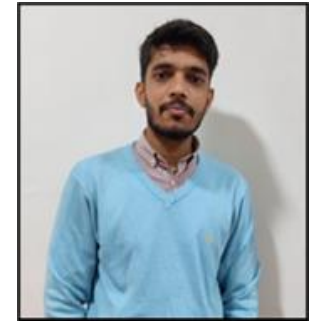

Sunil V. Barma is currently working as a Research Scholar at the School of Energy Studies, Savitribai Phule Pune University, Pune 411007 (India). His research interest area includes Structural, Optical and Photoelectrochemical investigation of binary, ternary and quaternary semiconductors and their heterostructures for Photovoltaic and water splitting application.

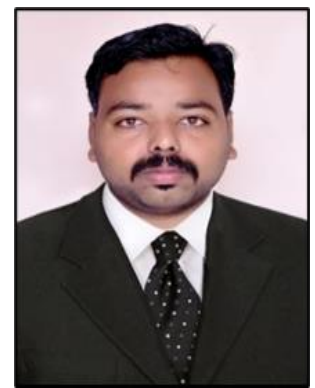

Avinash V. Rokade completed two Masters Degrees (M.Sc. in 2012 and M.Phil. in 2014) and during he has gained some expertise in nanomaterial's synthesis by the chemical route and their application for photocatalytic water splitting for hydrogen gas evolution. He was awarded NREF (National Renewable Energy Fellowship) of MNRE, Govt. of India to pursue Ph. D. at School of Energy, Savitribai Phule Pune University from 2014 to 2018. He has been awarded a Ph. D. in physics from the Department of Physics, Savitribai Phule Pune University, Pune in 2018. He has published more than 30 research articles and 2 book chapters in peer-reviewed journals. Presently, he is Assistant Professor at the School of Energy Studies, Savitribai Phule Pune University, Pune working in the field of optoelectronic devices, mainly to improve PEC the efficiency with help of $1 D, 2 D$, and $3 D$ nanostructures and investigation of their interfacial properties via Photo Electrochemical Impedance Spectroscopy, Cyclic Voltammetry, Chrono methods, and Mott-Schottky analysis for photo-generated charge-transfer dynamics.

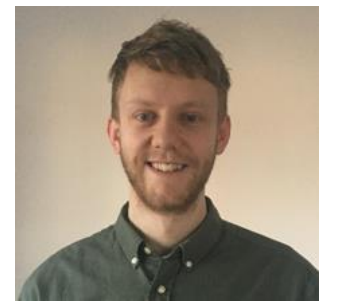

Russell $\boldsymbol{W}$. Cross is a graduate from Cardiff University, where he gained $M S c$ in Catalysis and a BSc in Chemistry degrees. Russell's PhD research involves computer-aided design of transition metal phosphides for efficient hydrogen evolution reaction. He is also working on the rational design of bimetallic Ni-based catalyst for direct hydrazine fuel cell (DHFC) technology.

Publisher's Note: Engineered Science Publisher remains neutral with regard to jurisdictional claims in published maps and institutional affiliations. 